\title{
PROBABILISTIC LIQUEFACTION POTENTIAL ANALYSIS OF SAN FERNANDO PAMPANGA, PHILIPPINES USING SEMI- MARKOV CHAIN
}

\author{
*Charles Julius Oliquino ${ }^{1}$, and Jonathan Dungca ${ }^{2}$ \\ ${ }^{1-2}$ Civil Engineering Department, De La Salle University, Manila, Philippines \\ *Corresponding Author, Received: 20 Sept. 2021, Revised: 20 Oct. 2021, Accepted: 23 Nov. 2021
}

\begin{abstract}
The Philippines is prone to earthquakes, making the liquefaction opportunity is higher compared to other regions and countries. Existing models in calculating the probability of liquefaction are memoryless which does not consider the current and previous conditions in predicting the future values, hence, a method utilizing a semi-Markov chain was used. The city of San Fernando, Pampanga in the Philippines was considered as the study area The liquefaction potential map was developed by identifying the acceleration to trigger liquefaction based on the susceptibility computation. Then, the liquefaction opportunity was taken from the probabilistic seismic hazard analysis (PSHA) to determine the probability that the acceleration to initiate liquefaction will be exceeded. In addition, the seismic amplification factor was considered in the study, as well as an updated ground motion prediction equation. A semi-Markov chain was used in calculating the liquefaction potential. From the study, the liquefaction potential maps were developed, and it can be inferred that most parts of the province's capital have a high liquefaction potential in the next fifty years.
\end{abstract}

Keywords: Liquefaction Potential, Liquefaction Opportunity, Liquefaction Susceptibility, PSHA, Semi-Markov Chain, Philippines

\section{INTRODUCTION}

The Philippines is one of the most volcanically and seismically active regions. The nation has recorded numerous big earthquakes in the last 400 years. Bird and Bommer [1] reported the secondary causes of damages to buildings were made up of minor landslides, minor tsunami, minor ground shaking, fault rupture, and liquefaction. From the study, liquefaction made up $43 \%$ of the secondary causes of damages and it was the highest contributor among the lists. Further, the study also quantified the causes of damages to transportation. For both the significant and moderate transportation damages, liquefaction was consistent in being the biggest contributor to the damages. For the damages to utilities, liquefaction contributed the second largest to the damages with a 37\% impact.

Pampanga is a province in the Central Luzon area of the Philippines, and it is near Metro Manila, the regional capital of the Philippines as shown in Fig. 1. The city of San Fernando is the province's capital. It is the center of businesses, livelihoods and it is a highly urbanized area with multiple leisure parks, malls, and other residential areas. It is also expected that the city will continue to expand its residential area in the coming years. From its geographic location, the nearest active volcano is mount Pinatubo, and a possibly active volcano, mount Arayat, is both around $25 \mathrm{~km}$ away from the city. It is also near multiple fault lines such as the
Iba Fault, East Zambales Fault, and the West Valley Fault. Since these faults can produce magnitude 7 or 8 earthquakes, the opportunity of liquefaction is high, hence, it is important to know the probability of earthquake-induced liquefaction of the province in the succeeding years.

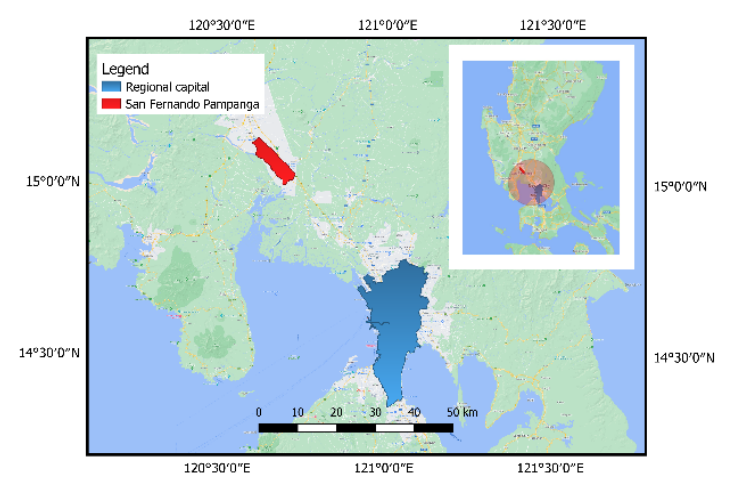

Fig.1 Location of Pampanga relative to the nation's regional capital

There are some literatures [2-6] that have already proposed a method in computing the probability of liquefaction but most of the existing models were memoryless which does not consider the current and previous conditions in predicting the future values, hence, the proposed method of utilizing the semi-Markov chain which considers the posterior distribution. 


\section{RESEARCH SIGNIFICANCE}

The study contributed technical and academic knowledge in utilizing the semi-Markov chain in developing a probabilistic liquefaction potential map and to test this method, a liquefaction potential map was developed for the City of San Fernando. In addition, the study informed local authorities regarding the potential of earthquake-induced liquefaction to minimize the risk of the city to liquefaction.

\section{METHODOLOGY}

\subsection{Data Gathering}

The earthquake sources within the $150 \mathrm{~km}$ radius [7] of the study area were determined by plotting the fault lines and drawing a $150 \mathrm{~km}$ radius from the center of the study area. The earthquake records [8,9] of a minimum magnitude 5.2 [10] from the considered sources were collected. The fault sources and the records of earthquakes were plotted as shown in Fig. 2.

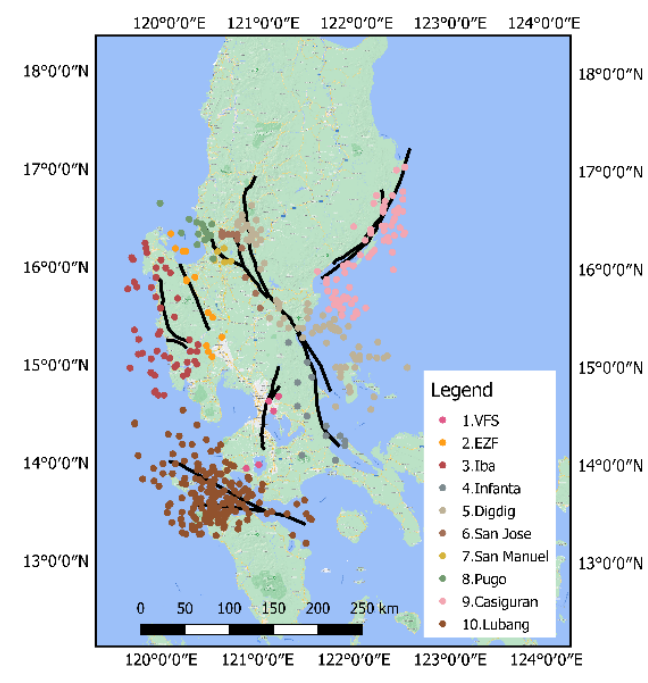

Fig.2 Earthquake sources and records of earthquake in the study area

The surface, body wave [11], and local magnitudes [12] were converted to the respective moment magnitudes using Eq. (1), Eq. (2), and Eq. (3).

$M_{w}=e^{-0.222+0.233 M_{s}}+2.863$
$M_{w}=e^{-4.664+0.859 M_{b}}+4.555$
$M_{w}=0.7814+0.9993 M_{L}$

The characteristics of the earthquake sources [13] were also gathered. It includes the tectonics, geometry style, length, width, depth, and dip angle. Further, borehole data were congregated from the available public projects and some of the local geotechnical firms. The relevant soil information was used for the calculation of the acceleration to trigger liquefaction.

\subsection{Data Analysis}

3.2.1 Acceleration to trigger liquefaction from liquefaction susceptibility equations

With the borehole data collected, the computation for the liquefaction susceptibility was performed. The whole process involved the computation of the seismic amplification factor, the initial liquefaction susceptibility based on the compositional criteria, the corrected SPT-N values for clean sands, and the acceleration required for the soil to liquefy. For the amplification factor, the shear wave velocities based on SPT N-value [14] or RQD [15] were first computed using Eq. (4) or using linear interpolations of the values in table 1 .

$$
V_{S}=77.13 N^{0.377}
$$

Table 1 Shear wave velocity using RQD

\begin{tabular}{cc}
\hline RQD (\%) & $\begin{array}{c}\text { Shear Wave } \\
\text { Velocity, } \mathrm{V}_{\mathrm{s}}(\mathrm{m} / \mathrm{s})\end{array}$ \\
\hline $0<\mathrm{RQD} \leq 50$ & 600 \\
$\mathrm{RQD}=65$ & 760 \\
$\mathrm{RQD}=80$ & 1500 \\
$\mathrm{RQD}=90$ & 2500 \\
$\mathrm{RQD}=100$ & 3400 \\
\hline
\end{tabular}

With the shear wave velocity in each layer, the approximate value of $\mathrm{Vs}_{30}$ [16], which is the average shear wave velocity in the first 30 meters is calculated using Eq. (5).

$V_{s 30}=\frac{\sum_{i=1}^{N} h_{i}}{\sum_{i=1}^{N} \frac{h_{i}}{v_{s i}}}$

The amplification factor [16,17] was evaluated using Eq. (6) and Eq. (7). The equations used considered the linear and non-linear effects of soil.

For $\boldsymbol{V}_{\boldsymbol{s 3 0}}<\boldsymbol{V}_{\text {ref }}$

$\ln (A F)=a_{1} \ln \left(\frac{V_{s 30}}{V_{r e f}}\right)+a_{2}\left[\ln \left(\frac{V_{s 30}}{V_{r e f}}\right)\right]^{2}+$

$a_{3} \ln \left(\frac{V_{\text {ratio }}}{1.4}\right)+b_{1} \ln \left(\frac{P A_{\text {rock }}+c}{c}\right)+$

$b_{2} \ln \left(\frac{\max \left(P A_{\text {rock }} P A_{\text {rockmin }}\right)}{P A_{\text {rockmin }}}\right) x \ln \left(\frac{V_{\text {ratio }}}{1.4}\right)$

For $\boldsymbol{V}_{s 30} \geq \boldsymbol{V}_{\text {ref }}$ :

$\ln (A F)=b_{1} \ln \left(\frac{P A_{\text {rock }}+c}{c}\right)+$

$b_{2} \ln \left(\frac{\max \left(P A_{\text {rock }} P A_{\text {rockmin }}\right)}{P A_{\text {rockmin }}}\right) x \ln \left(\frac{V_{\text {ratio }}}{1.4}\right)$ 
The initial peak ground acceleration [18] used for the amplification factor calculation is defined in Eq. (8).

$\log (A)=0.41 M-\log \left(R+0.032 \times 10^{0.41 M}\right)$

$-0.0034 R+1.3, \sigma_{\log A}=0.21$

The parameters $a_{3}$ and $b_{1}$ used in the calculation were taken from Eq. (9) and Eq. (10) as shown below.

$a_{3}=\left\{\begin{aligned} a_{0}, & \text { if } V_{s 30} \leq V_{a} \\ a_{0}-\frac{a_{0}}{V_{b}-V_{a}} x\left(V_{s 30}-V_{a}\right), & \text { if } V_{a}<V_{s 30} \leq V_{b} \\ 0, & \text { if } V_{s 30}>V_{b}\end{aligned}\right.$

$b_{1}=\left\{\begin{aligned} b_{01}, & \text { if } V_{s 30} \leq V_{1} \\ b_{01}+\frac{b_{02}-b_{01}}{\ln \left(\frac{V_{2}}{V_{1}}\right)} x \ln \left(\frac{V s_{30}}{V_{1}}\right), & \text { if } V_{1}<V_{s 30} \leq V_{2} \\ b_{02}, & \text { if } V_{s 30}>V_{2}\end{aligned}\right.$

The values of the other constants can be seen in table 2.

Table 2 Constants in the amplification factor calculation

\begin{tabular}{clcl}
\hline Constant & Values & Constant & Values \\
\hline $\mathrm{a}_{1}$ & -0.69 & $\mathrm{~V}_{1}$ & 184 \\
$\mathrm{a}_{2}$ & -0.13 & $\mathrm{~V}_{2}$ & 184 \\
$\mathrm{a}_{0}$ & 0.34 & $\mathrm{c}$ & 0.10 \\
$\mathrm{~V}_{\mathrm{a}}$ & 176 & $\mathrm{~b}_{2}$ & 0.09 \\
$\mathrm{~V}_{\mathrm{b}}$ & 481 & $\mathrm{~V}_{\text {ref }}$ & 1000 \\
$\mathrm{~b}_{01}$ & -0.91 & $\mathrm{PA}_{\text {rockmin }}$ & 0.01 \\
$\mathrm{~b}_{02}$ & -0.24 & $\mathrm{~V}_{\text {ratio }}$ & 2.5 \\
\hline
\end{tabular}

The relationship between the amplification factor, peak ground acceleration for bedrock, and adjusted PGA [16] is shown in Eq. (11).

$\ln (P G A)=\ln (A F)+\ln \left(P A_{\text {rock }}\right)$

Then, the initial liquefaction susceptibility was determined using the compositional criteria. The soil layer is initially classified as susceptible to liquefaction if all the criteria in Eq. (12) were satisfied [19]. The input values in the relationship are the water content, liquid limit, and plasticity index.

$W_{c}>0.85 L L, \quad L L<37, \quad P I<7$

The unit weight of soil in each layer is an important parameter in the correction of the SPT. It is also the basis for the computation of the total and effective stresses which is used in the computation of the acceleration. A method of predicting the geotechnical parameters using various machine learning techniques were utilized [20]. The summary of the correlations is shown in table 3 . The equations have an input of $\mathrm{N}$-value which was taken from the borehole data.

Table 3 Unit weight computations based on $\mathrm{N}$ value

\begin{tabular}{cccc}
\hline $\begin{array}{c}\text { Soil } \\
\text { Type }\end{array}$ & $\begin{array}{c}\text { Soil } \\
\text { Property }\end{array}$ & $\begin{array}{c}\text { Unit weight } \\
\left(\text { in } \mathrm{kg} / \mathrm{m}^{3}\right)\end{array}$ & $\begin{array}{c}\text { Range } \\
\text { of N- } \\
\text { value }\end{array}$ \\
\hline Coarse & Saturated & $(0.0096 * \mathrm{~N}+1.5001)$ & $1-39$ \\
Coarse & Saturated & $(0.0141 * \mathrm{~N}+1.3726)$ & $40-50$ \\
Coarse & Moist & $(0.0068 * \mathrm{~N}+1.5554)$ & $1-50$ \\
Fine & Saturated & $(0.0080 * \mathrm{~N}+1.7202)$ & $1-50$ \\
Fine & Moist & $(0.0114 * \mathrm{~N}+1.2488)$ & $1-50$ \\
\hline
\end{tabular}

For each susceptible layer based on the compositional criteria, the corrected SPT $\left(\mathrm{N}_{1}\right)_{60}$ value [21,22] was evaluated using Eq. (13), and the clean sand adjustment [21] was determined using Eq. (14). The final SPT N-value corrected for clean sands was done using Eq. (15).

$$
\begin{aligned}
& \left(N_{1}\right)_{60}=C_{N} C_{E} C_{R} C_{B} C_{S} N_{m} \\
& \Delta\left(N_{1}\right)_{60}=\exp \left(1.63+\frac{9.7}{F C+0.01}-\left(\frac{15.7}{F C+0.01}\right)^{2}\right) \\
& \left(N_{1}\right)_{60 c s}=\left(N_{1}\right)_{60}+\Delta\left(N_{1}\right)_{60}
\end{aligned}
$$

where: $C_{N}$ is the overburden correction factor, $C_{E}$ is the hammer energy correction factor, $C_{R}$ is the correction for rod factor, $C_{B}$ is the nonstandard borehole correction, $\mathrm{C}_{\mathrm{S}}$ is the split spoon correction factor, $\mathrm{N}_{\mathrm{m}}$ is the standard $\mathrm{N}$ value, and FC is the percent fines content.

For each susceptible sub-layer, the total stresses and effective stresses of each soil layer were computed. Then, the correction factors for the cyclic stress ratio and cyclic resistance ratio were computed: the overburden correction factor, the stress reduction factor, and the magnitude scaling factor [21] was determined using Eq. (16), Eq. (17), and Eq. (18), respectively.

$$
\begin{gathered}
\left\{\begin{array}{l}
\boldsymbol{K}_{\boldsymbol{\sigma}}=\mathbf{1}-\boldsymbol{C}_{\boldsymbol{\sigma}} \ln \left(\frac{\boldsymbol{\sigma}_{v}^{\prime}}{\boldsymbol{P}_{\boldsymbol{a}}}\right) \leq \mathbf{1 . 1} \\
\boldsymbol{C}_{\boldsymbol{\sigma}}=\frac{\mathbf{1}}{\mathbf{1 8 . 9 - 2 . 5 5} \sqrt{\left(\boldsymbol{N}_{\mathbf{1}}\right)_{\mathbf{6 0} c s}} \leq \mathbf{0 . 3}}
\end{array}\right. \\
\left\{\begin{array}{c}
r_{d}=\exp [\alpha(z)+\beta(z) \cdot M] \\
\alpha(z)=-1.012-1.126 \sin \left(\frac{z}{11.73}+5.133\right) ; \\
\beta(z)=0.106+0.118 \sin \left(\frac{z}{11.28}+5.142\right) ;
\end{array}\right.
\end{gathered}
$$


$M S F=6.9 \cdot \exp \left(\frac{-M}{4}\right)-0.058 \leq 1.8$

where: $\sigma^{\prime}{ }_{\mathrm{v}}$ is the effective stress at the layer considered, $\mathrm{P}_{\mathrm{a}}$ is the atmospheric pressure, $\mathrm{z}$ is the depth below the ground surface, and $M$ is the magnitude considered.

In each layer considered, the non-adjusted and corrected cyclic resistance ratio, CRR [21] was evaluated using Eq. (19) and Eq. (20), respectively.

$C R R_{n a}=\exp \left(\begin{array}{c}\frac{\left(N_{1}\right)_{60 c s}}{14.1}+\left(\frac{\left(N_{1}\right)_{60 c s}}{126}\right)^{2}- \\ \left(\frac{\left(N_{1}\right)_{60 c s}}{23.6}\right)^{3}+\left(\frac{\left(N_{1}\right)_{60 c s}}{25.4}\right)^{4}- \\ 2.8\end{array}\right)$

$C R R_{M \cdot \sigma_{v}^{\prime}}=C R R_{n a} \cdot M S F \cdot K_{\sigma}$

The value of the cyclic stress ratio, CSR [21] was solved by using Eq. (21). Then, the acceleration to trigger liquefaction was determined by isolating the value of the required acceleration, $\mathrm{a}_{\max }$ in $\mathrm{Eq}$. (22). The computed acceleration will be used as the parameter for the liquefaction potential calculations [23].

$F S_{l i q}=\frac{C R R_{M \cdot \sigma_{v}^{\prime}}}{{ }^{C S R}{ }_{M \cdot \sigma_{v}^{\prime}}^{\prime}}$

$C S R_{M \cdot \sigma_{v}^{\prime}}=0.65 \frac{\sigma_{v}}{\sigma_{v}^{\prime}} \frac{a_{\max }}{g} r_{d}$

\subsubsection{Liquefaction opportunity based on probabilistic seismic hazard analysis}

After obtaining the required acceleration to trigger liquefaction, the said acceleration will be used as an input value in the probabilistic seismic hazard analysis (PSHA) [24] to determine the probability that the certain acceleration will be exceeded in a given year. The PSHA was expressed using the total probability theorem formula as shown in Eq. (23).

$\lambda[Y \geq y]=\sum_{i=1}^{N_{S}} v_{i} \sum_{j=1}^{N_{m}} \sum_{k=1}^{N_{r}} P\left[Y>y^{*} \mid m_{j}, r_{k}\right] P[M=$ $\left.m_{j}\right] P\left[R=r_{k} \mid m_{j}\right]$

where: $\lambda[Y \geq y]$ is the total mean annual rate of exceedance for the peak ground acceleration, $\mathrm{y}^{*}, \mathrm{~N}_{\mathrm{s}}$ is the number of earthquake sources, $\mathrm{i}$ at the site or region of interest, $\mathrm{N}_{\mathrm{m}}$ is the number of magnitude intervals, $\mathrm{j}$ to be considered, $\mathrm{N}_{\mathrm{r}}$ is the number of distance intervals, $\mathrm{k}$ to be considered, $\mathrm{v}_{\mathrm{i}}$ is the mean rate of exceedance for magnitude for source, $i$, $\mathrm{P}\left[\mathrm{Y}>\mathrm{y}^{*} \mid \mathrm{m}_{\mathrm{j}}, \mathrm{r}_{\mathrm{k}}\right]$ is the probability that the peak acceleration level is exceeded given the probability of magnitude, $\mathrm{j}$ and distance, $\mathrm{r}, \mathrm{P}\left[\mathrm{M}=\mathrm{m}_{\mathrm{j}}\right]$ is the probability for the magnitude, $M$ occurs in the magnitude intervals, $m_{j}$, and $P\left[R=r_{k} \mid m_{j}\right]$ is the probability for the distance, $\mathrm{R}$.

The probability distribution function for distance was determined based on a uniform distribution. It is assumed that the fault rupture followed the finite fault rupture model which asserts that an earthquake-generated at the center was of the same magnitude in the rupture length or the rupture area. The ends of the faults are extended using the relationship for the linear sources [25] shown in Eq. (24) while the formula for the areal sources [26] was done using Eq. (25). Further, the length of the rupture based on the down-dip width [27] was computed using Eq. (26).

$\log L=0.74 M_{w}-3.55 ; \sigma_{\log L}=0.23$
$M=4.532+0.887 \log L ; \sigma_{\log M}=0.344$
$L=2 W$

Then, the difference between the nearest $\left(r_{\min }\right)$ and the farthest $\left(r_{\max }\right)$ from the site to linear/areal source was solved. A uniform probability distribution function (PDF) was created by subdividing the difference into 10 intervals, then the $1 \mathrm{~km}$ strip was tallied in each fault source.

For the probability distribution for the magnitude, the annual rate of an earthquake in each fault source was then computed. The distribution of the magnitudes of the earthquakes was recorded using a class size of 0.6 [28] starting with a magnitude 5.2 earthquake. The number of earthquakes exceeding the minimum magnitude in each class was tallied. Then, the logarithm of the ratio of the number of earthquakes exceeding the minimum value to the number of years passed since the first earthquake, and the midpoint values of the classes were plotted in a graph.

A connecting line was used to connect the points in the graph and an approximate linear regression was drawn based on the points plotted. The linear graph developed was the Gutenberg-Richter graph. A graph using the Digdig Fault in the Philippine Fault Zone is shown in figure 3. The computation for the probability distribution function for the bounded Gutenberg-Richter relationship is done using Eq. (27), and the probability that of an earthquake with a minimum and maximum magnitude is calculated using Eq. (28). The beta value was derived from the slope of the graph following Eq. (29).

$$
\begin{aligned}
& f_{M}(m)=\frac{\beta \exp \left(-\beta\left(m-m_{0}\right)\right)}{1-\exp \left(-\beta\left(m_{\max }-m_{0}\right)\right)} \\
& P\left[m_{l} \leq m \leq m_{u}\right]=\int_{m_{l}}^{m_{u}} f_{M}(m) d m \\
& =f_{M}\left(\frac{m_{l}+m_{u}}{2}\right)\left(m_{u}-m_{l}\right)
\end{aligned}
$$

$\beta=2.303 b$ 
where: $m_{0}$ is the minimum magnitude of an earthquake, $\mathrm{m}_{\max }$ is the maximum possible magnitude of an earthquake, $m$ is the magnitude of an earthquake considered, $b$ is the value from the regression analysis, $m_{l}$ is the minimum magnitude in each interval, and $\mathrm{m}_{\mathrm{u}}$ is the maximum magnitude in each interval.

For the computation of the probability of exceeding the acceleration to trigger liquefaction given a distance-magnitude pair, the predicted acceleration of an earthquake [29] given a combination of distance and magnitude was computed using Eq. (30). The comprehensive computation for the ground motion prediction equation was done using the spreadsheet from the Pacific Engineering Earthquake Research (PEER) Center [30].

$$
\begin{aligned}
& \ln S a(g)=f_{1}\left(M, R_{\text {rup }}\right)+F_{R V} f_{7}(M)+F_{N} f_{8}(M) \\
& +\boldsymbol{F}_{\boldsymbol{A S}} \boldsymbol{f}_{\mathbf{1 1}}\left(\boldsymbol{C R}_{\boldsymbol{j b}}\right)+\boldsymbol{f}_{\mathbf{5}}\left(\widehat{\boldsymbol{S a}}_{1180}, \boldsymbol{V}_{\boldsymbol{s 3 0}}\right) \\
& +\boldsymbol{F}_{\boldsymbol{H}} \boldsymbol{f}_{\mathbf{4}}\left(\boldsymbol{R}_{\boldsymbol{j} \boldsymbol{b}}, \boldsymbol{R}_{\text {rup }}, \boldsymbol{R}_{\boldsymbol{x}}, \boldsymbol{R}_{\boldsymbol{y} \mathbf{0}}, \boldsymbol{W}, \boldsymbol{d i p}, \boldsymbol{Z}_{\boldsymbol{T O R}}, \boldsymbol{M}\right)+ \\
& \boldsymbol{f}_{\mathbf{6}}\left(\boldsymbol{Z}_{\boldsymbol{T O R}}\right)+\boldsymbol{f}_{\mathbf{1 0}}\left(\boldsymbol{Z}_{\mathbf{1 . 0}}, \boldsymbol{V}_{\boldsymbol{s 3 0}}\right)+ \\
& \operatorname{Regional}\left(\boldsymbol{V}_{\boldsymbol{s 3 0}}, \boldsymbol{R}_{\text {rup }}\right)
\end{aligned}
$$

The probability of an earthquake exceeded the mean PHA was computed using the normal distribution curve with the standard score, $\mathrm{z}$, given by the cumulative distribution function of Eq. (31).

$Z=\frac{\log a-\log A}{\sigma_{\log A}}$

For each distance - magnitude, the product of the probability that the earthquake will happen at a certain distance, the probability that a certain magnitude will happen, and the probability that the ground motion will be exceeded was computed following the concept of conditional probabilities. Then, the values were added to determine the total mean annual rate of exceedance which is also taken as the probability of exceedance for the given fault and location.

\subsubsection{Liquefaction potential using semi-Markov chain}

The Markov Chain is a probability process where the posterior distribution is used to predict future events. Semi-Markov chains are a type of Markov process, but it considers a finite interval of time during the transition period making it a timedependent stochastic process.

The liquefaction potential is the calculation of the probabilities that an earthquake triggering liquefaction can happen in the next couple of years. The initial probability matrix [31] was defined as the total mean annual rate of exceedance of an earthquake triggering liquefaction and its complement. The initial matrix is done using Eq.
(32). The two values were used as the parameters in the transitional matrix using Eq. (33). The computation for the liquefaction potential for each year was attained using Eq. (34) following the concept of the semi-Markov chain.

$[P]=[p(f, s) \quad p(f, f)]$

$[\boldsymbol{T}]^{\boldsymbol{n}}=\frac{\mathbf{1}}{2-\boldsymbol{p}(\boldsymbol{s}, \boldsymbol{f})-\boldsymbol{p}(\boldsymbol{f}, \boldsymbol{f})}\left[\begin{array}{cc}\mathbf{1}-\boldsymbol{p}(\boldsymbol{f}, \boldsymbol{f}) & \mathbf{1}-\boldsymbol{p}(\boldsymbol{s}, \boldsymbol{f}) \\ \mathbf{1}-\boldsymbol{p}(\boldsymbol{f}, \boldsymbol{f}) & \mathbf{1}-\boldsymbol{p}(\boldsymbol{s}, \boldsymbol{f})\end{array}\right]$
$+\frac{[p(s, f)+p(f, f)-1]^{n}}{2-p(s, f)-p(f, f)}\left[\begin{array}{cc}1-p(s, f) & -(1-p(s, f)) \\ -(1-p(f, f)) & 1-p(f, f)\end{array}\right]$

$[L]=[P] x[T]^{n}$

where: s(success) is the annual rate of occurrence of an earthquake that could produce liquefaction, $f$ (failure) is the annual rate of non-occurrence of an earthquake that could produce liquefaction or no earthquake at all, $\mathrm{p}(\mathrm{s}, \mathrm{s})$ is the probability of success followed by another success, $p(s, f)$ is the probability of success followed by failure, $p(f, s)$ is the probability of failure followed by success, $p(f, f)$ is the probability of failure followed by another failure, and $\mathrm{n}$ is the number of years from the year considered.

The probability of an earthquake triggering liquefaction was computed each year for fifty years. To better show the gradual increase of the liquefaction potential, a probabilistic map for the next $5,10,25$, and 50 years shall be drawn.

\section{RESULTS AND DISCUSSION}

\subsection{Liquefaction Potential Map}

Using the liquefaction potential computation for each borehole data, the liquefaction potential map was drawn. The liquefaction potential for the next five (5) years is shown in Fig. 3. The maximum probability (in percent) in the map was 5.6 and it was taken as the maximum value of the liquefaction potential excluding the outliers. The same maximum value was used for other liquefaction potential maps. From the figure, it can be observed that the lower portion and the middle portion have a high liquefaction potential for the next five years. It should be noted that there are no available borehole data within the top-most left section, hence, the liquefaction potential map may not represent the actual condition for the said portion. The liquefaction potential maps for ten (10), twenty-five (25), and fifty (50) years are also shown in Figs. 46.

In the map for five (5) years, only the lower 
portion has a high liquefaction potential while a moderate liquefaction potential can be seen in the middle portion of the study area. The high value of liquefaction potential in the lower portion of the area may be attributed to the looseness of soil near bodies of water which resulted in a relatively low SPT N-value compared to other areas.

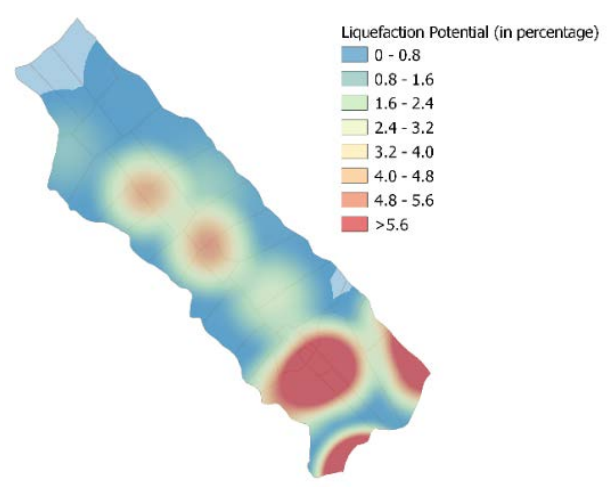

Fig.3 Liquefaction potential map for the next five (5) years

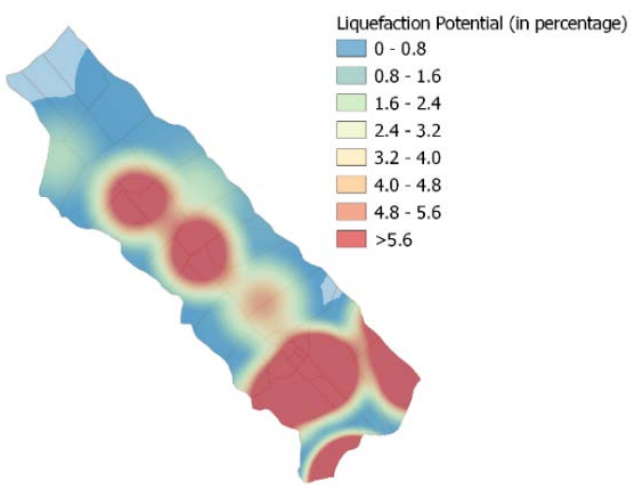

Fig.4 Liquefaction potential map for the next ten (10) years

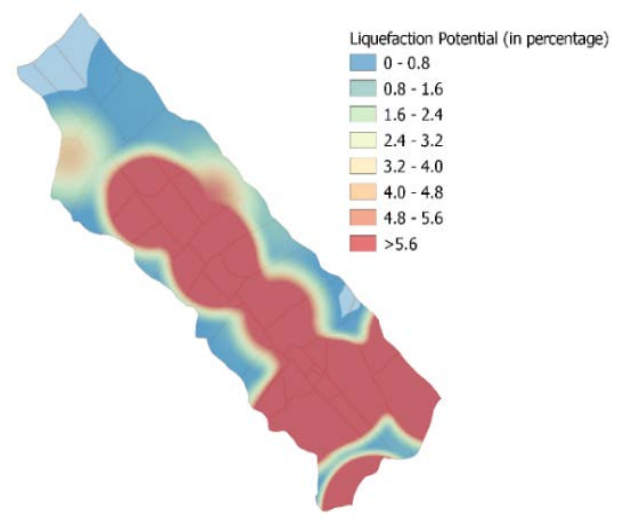

Fig.5 Liquefaction potential map for the next twenty-five (25) years

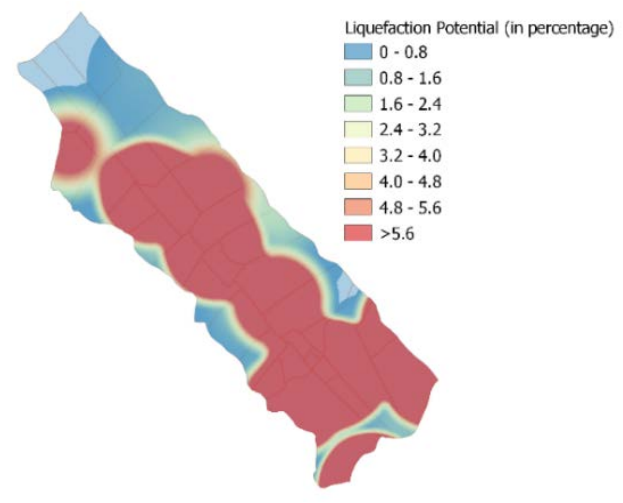

Fig.6 Liquefaction potential map for the next fifty (50) years

For the map for ten (10) years, a significant increase from moderate to high liquefaction potential map can be seen in the middle portion of the area but the majority middle portion was not yet considered as an area with high liquefaction potential.

In the map for twenty-five (25) years, most of the middle portion of the area was classified as an area with a high liquefaction potential. In addition, the area in the top left portion was being reclassified to a potential of moderate liquefaction.

Finally, the map for fifty (50) years showed that most of the upper left, middle and lower portions of the study area showed a high liquefaction potential. In general, as time passes by, the liquefaction potential for the study area became larger and larger.

\subsection{Deaggregation}

It is important to determine which fault source and magnitude contributed the most to the liquefaction potential. The deaggregation of the fault sources and magnitude is shown in Fig. 7.

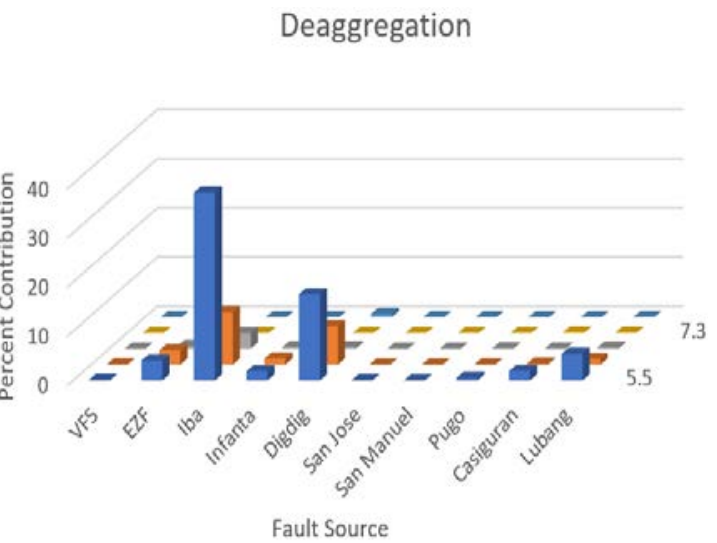

Fig.7 Deaggregation for fault source and magnitude 
The deaggregation was done by determining which fault source contributed the most to the annual rate of exceedance. Then, the contribution of the moment magnitudes in each fault source was also taken into consideration. From the figure, it was concluded that the Iba fault and at moment magnitudes 5.2 to 5.8 contributed the most to the liquefaction potential. In addition, it should be noted that the Digdig Fault from the Philippine Fault Zone contributed the second-highest in the liquefaction computation while the third-highest is from the Iba fault with a magnitude interval of 5.8 to 6.4 .

\section{CONCLUSION}

The presence of seismic activities and hazards in the Philippines contributed to the need for studies such as this. The history of liquefaction in the said province and the weight of the city's contribution in terms of economic and residential shares were some of the main factors for the assessment of the liquefaction potential. Since the study area is relatively close to the nation's capital, continuous development and urbanization are happening in the province, where the City of San Fernando belongs, which is another factor considered in the study.

In the analysis, the acceleration to trigger liquefaction was used as the target acceleration in the liquefaction opportunity. The probabilistic earthquake-induced liquefaction potential computation in each $5,10,25$, and 50 years was developed using a semi-Markov chain.

A liquefaction potential map was using QGIS. From the liquefaction potential maps, the following was concluded:

- $\quad$ for five (5) years, it was observed that the lower portion of the province's capital has already a high potential for liquefaction;

- for ten (10) years, a significant increase from moderate to high liquefaction potential can be seen in the middle portion of the study area but the majority of the middle portion was not yet considered as an area with high liquefaction potential;

- for twenty-five (25) years, the majority of the middle portion was classified as an area with a high liquefaction potential;

- $\quad$ going further, the map for fifty (50) years recommends that the liquefaction potential is high for the majority parts of the city: the lower part, the middle part, and the upper left areas.

From the deaggregation, it was observed that earthquakes near the Iba fault are the main sources of liquefaction opportunity for the city.

\section{ACKNOWLEDGMENTS}

The author would like to thank the Department of Science and Technology-Engineering Research and Development for Technology (DOST-ERDT) for funding the research.

\section{REFERENCES}

[1] Bird, J. F., \& Bommer, J. J., Earthquake losses due to ground failure. Engineering geology, Vol.75, Issue 2, 2004, pp.147-179.

[2] Fenton, G. A., and Vanmarcke, E. H., Spatial variation in liquefaction risk. Geotechnique, Vol. 48, No. 6, 1998, pp.819-831.

[3] Goh, A. T., Seismic liquefaction potential assessed by neural networks. Journal of Geotechnical engineering, Vol. 120, No. 9, 1994, pp.1467-1480.

[4] Jha, S. K., and Suzuki, K., Reliability analysis of soil liquefaction based on standard penetration test. Computers and Geotechnics, Vol. 36, No. 4, 2009, pp.589-596.

[5] Juang, C. H., Jiang, T., and Andrus, R. D., Assessing probability-based methods for liquefaction potential evaluation. Journal of Geotechnical and Geoenvironmental Engineering, Vol. 128, No. 7, 2002, pp.580-589.

[6] Johari, A., Javadi, A. A., Makiabadi, M. H., and Khodaparast, A. R., Reliability assessment of liquefaction potential using the jointly distributed random variables method. Soil Dynamics and Earthquake Engineering, Vol. 38, 2012, pp.81-87.

[7] Youd, T. L., and Perkins, D. M., Mapping liquefaction-induced ground failure potential. Journal of the Soil Mechanics and Foundations Division, Vol. 104, No. 4, 1978, pp.433-446.

[8] Bautista, M. L. P., and Oike, K., Estimation of the magnitudes and epicenters of Philippine historical earthquakes. Tectonophysics, 317(12), 2000, pp.137-169.

[9] PHIVOLCS (Philippines Institute of Volcanology and Seismology). Catalogue of Metro Manila Earthquakes, magnitude 5.2 and above (1907 - 2021), 2021.

[10]SEASEE (Southeast Asia Association of Seismology and Earthquake Engineering), Series on Seismology vol IV, 1985.

[11] Giacomo, D., Bondár, I., Storchak, D. A., Engdahl, E. R., Bormann, P., and Harris, J., ISCGEM: Global Instrumental Earthquake Catalogue (1900-2009), III. Re-computed MS and mb, proxy MW, final magnitude composition and completeness assessment. Physics of the Earth and Planetary Interiors, Vol. 239, 2015, pp.33-47.

[12] Idriss, I. M., Evaluating seismic risk in 
engineering practice. Proceedings of the 11th International Conference on Soil Mechanics and Soil Engineering, San Francisco, 1985.

[13] JICA (Japan International Cooperation Agency). Metropolitan Manila Impact Reduction Study, JR-04-04, 2004.

[14] Marto, A., Tan, C. S., and Leong, T. K., Universal correlation of shear wave velocity and standard penetration resistance. Electronic Journal of Geotechnical Engineering, Vol. 18, 2013, pp.2727-2738.

[15]Hunt, R. E., Geotechnical engineering investigation manual (No. 624.151 H86). New York: McGraw-Hill, 1984.

[16] Navidi, S., Site amplification model for use in ground motion prediction equations. The University of Texas at Austin, 2012.

[17] Dungca, J. R., and Macaraeg, C. J., Development of a Reference for Seismic Amplification: The Case of Metro Manila. In 19th Congress of International Association for Bridge and Structural Engineering, 2016.

[18]Fukushima, Y., and Tanaka, T., A new attenuation relation for peak horizontal acceleration of strong earthquake ground motion in Japan. Bulletin of the seismological Society of America, Vol. 80, No. 4, 1990, pp.757-783.

[19] Idriss, I. M., and Boulanger, R. W., Semiempirical procedures for evaluating liquefaction potential during earthquakes. Soil dynamics and earthquake engineering, Vol. 26, Issues 2-4, 2006, pp.115-130.

[20] Puri, N., Prasad, H. D., and Jain, A., Prediction of geotechnical parameters using machine learning techniques. Procedia Computer Science, Vol. 125, 2018, pp.509-517.

[21] Boulanger, R. W., and Idriss, I. M., CPT and SPT based liquefaction triggering procedures. Report No. UCD/CGM.-14, 1, 2014.

[22] Seed, R. B., Cetin, K. O., Moss, R. E. S., Kammerer, A. M., Wu, J., Pestana, J. M., and Riemer, M. F., Recent advances in soil liquefaction engineering and seismic site response evaluation. In 4th Int. Conf. Recent Advanced in Geotechnical Earthquake Engineering and soil dynamics, San Diego, California, 2001.

[23] Dungca, J. R., and Chua, R. A. D.,
Development of a Probabilistic Liquefaction Potential Map for Metro Manila. International Journal of GEOMATE, Vol. 11, Issue 25, 2016, pp.2461-2467.

[24] Kramer, S. L., Geotechnical earthquake engineering. Pearson Education India, 1996.

[25] Wells, D. L., and Coppersmith, K. J., New empirical relationships among magnitude, rupture length, rupture width, rupture area, and surface displacement. Bulletin of the seismological Society of America, Vol. 84, No. 4, 1994, pp.974-1002.

[26] Singh, S. K., Bazan, E., and Esteva, L., Expected earthquake magnitude from a fault. Bulletin of the Seismological Society of America, Vol. 70, No. 3, 1980, pp.903-914.

[27] Sewell, R. T., Toro, G. R., and McGuire, R. K., Impact of ground motion characterization on conservatism and variability in seismic risk estimates (No. NUREG/CR-6467). Nuclear Regulatory Commission, Washington, DC (United States). Div. of Engineering Technology; Risk Engineering, Inc., Boulder, CO (United States),1996.

[28] Thenhaus, P. C., Hanson, S. L., Algermissen, S. T., Bautista, B. C., Bautista, M. L. P., Punongbayan, B. J., and Punongbayan, R. S., Estimates of the regional ground-motion hazard in the Philippines. Natural Disaster Mitigation in the Philippines (Proceedings), 1994, pp.71-98.

[29] Abrahamson, N. A., Silva, W. J., and Kamai, R., Summary of the ASK14 ground motion relation for active crustal regions. Earthquake Spectra, Vol. 30, No. 3, 2014, pp.1025-1055.

[30] Pacific Earthquake Engineering Research, PEER Strong Ground Motion Databases | Pacific Earthquake Engineering Research Center, 2014. https://peer.berkeley.edu/peerstrong-ground-motion-databases

[31] Vagliente, V. N., Forecasting the risk inherent in earthquake resistant design (Doctoral dissertation, Department of Civil Engineering, Stanford University), 1973.

Copyright (C) Int. J. of GEOMATE All rights reserved, including making copies unless permission is obtained from the copyright proprietors. 